\title{
A Study of Factors Associated with Relapse of Drinking during a 1 Year Follow-up: A Retrospective Cohort of 70 Males Treated as In-Patient for Alcohol Dependence Syndrome
}

\author{
Rena Stanley ${ }^{1}$, Sugaparaneetharan Ayyanar ${ }^{2}$, Ramanujam Venkatasamy ${ }^{3}$, J. Vijay Anto ${ }^{4}$ \\ ${ }^{1}$ Assistant Professor, Department of Psychiatry, Velammal Medical College, ${ }^{2}$ Assistant Professor, Department of Psychiatry, \\ Velammal Medical College, ${ }^{3}$ Professor and Head, Department of Psychiatry, Velammal Medical College, ${ }^{4}$ Assistant Professor \\ cum Statistician, Department of Community Medicine, Community Medicine, Velammal Medical College, Madurai, India
}

Corresponding author: Rena Stanley, Department of Psychiatry, Velammal Medical College, Anuppanadi, Madurai, 625009, India

DOI: http://dx.doi.org/10.21276/ijcmsr.2019.4.2.17

How to cite this article: Rena Stanley, Sugaparaneetharan Ayyanar, Ramanujam Venkatasamy, J. Vijay Anto. A study of factors associated with relapse of drinking during a 1 year follow-up: a retrospective cohort of 70 males treated as in-patient for alcohol dependence syndrome. International Journal of Contemporary Medicine Surgery and Radiology. 2019;4(2):B76-B79.

\section{A B S T R A C T}

Intoduction: Relapse is a multi-factorial phenomenon and most likely to result from a combination of various factors. This study was conducted to determine factors associated with relapse of drinking in patients who underwent deaddiction treatment programme.

Material and Methods: This is a retrospective cohort study was done in patients who were admitted for in-patient deaddiction care programme between September 2017 and February 2018. The in-patient charts of the subjects were retrieved from the medical records department. The SADQ score at admission, CIWA - Ar score and The Brief Substance Craving Score at the time of discharge were taken from the record.

Results: A total of 70 patients were recruited and the mean age of participant was $41.27 \pm 11.07$ years. At the end of 1 year the mean total no. of lapses was $9.9 \pm 12.67$ in the study population and the mean total number of relapses was $0.84 \pm 0.94$. The mean duration of complete abstinence last 1 year (CDA) in days was $272.43 \pm 109.12$. The mean no. of readmissions for de-addiction last 1 year was $0.23 \pm 0.57$ in the study population. Univariate analysis shows age at first drink in years, total duration of drinking in months and use of disulfiram and graduation as educational status are associated with higher odds of relapse. However, multiple regression model showed no statistically significant association.

Conclusion: The complete abstinence was seen only in $31.43 \%$ of the population

Keywords: Alcohol Dependence Syndrome, Life Events, Relapse, Craving, Impulsivity, Relapse

\section{INTRODUCTION}

Despite increased awareness of the risks of alcoholism, it continues to present a serious public health problem and constitutes one of the most frequent, preventable cause of morbidity and mortality. ${ }^{1}$ Continued excessive alcohol consumption can lead to the development of dependence that is associated with a withdrawal syndrome when alcohol consumption is ceased or substantially reduced. ${ }^{2}$

Relapse may be defined as the resumption of alcohol drinking following a prolonged period of abstinence. Clinically, vulnerability to relapse commonly is associated with an intense craving or desire to drink. ${ }^{2}$ Management of substance use disorders is riddled with multiple relapses. Research studies show that $65-70 \%$ of abstinent alcohol-dependence subjects relapse within 1 year. ${ }^{3,4}$ About $50 \%$ of detoxified alcohol users relapse within 3 months. There is evidence that approximately 90 percent of alcohol dependents are likely to experience at least one relapse over the 4-year period following treatment. ${ }^{5,6}$
Relapse is a multi-factorial phenomenon and most likely to result from a combination of various factors including the individual characteristics of the patient, the drug and environmental reinforcers. ${ }^{7}$ Among treated individuals, more severe alcohol-related problems and depressive symptoms, lack of self-efficacy, poor coping skills and readiness for change have been associated with relapse in short-term. ${ }^{7,8}$ Hence, in this study we propose to look for factors associated with relapse of drinking in patients who underwent deaddiction treatment as an in-patient in our hospital.

\section{MATERIAL AND METHODS}

This was a retrospective cohort study was done in patients who were admitted for in-patient de-addiction in "Nambikkai" addiction care programme between September 2017 and February 2018 were considered as the study population. The patient contact details were retrieved from the ward nominal register. Patients were contacted over phone and invited to participate in the study. The principal investigator reassessed 
the patient on the day of reporting for participation in the study. Ethical approval was obtained from institutional review board before the start of study.

\section{Inclusion criteria}

- $\quad$ Subject over 18 years

- Fulfilling the ICD 10 criteria for Alcohol dependence syndrome at admission

- No comorbid BPAD/psychotic illness or cognitive or neurological disorder

- No evidence of intellectual disability

- No other drug/narcotic use disorder other than nicotine

- Patients who report with reliable informant

- Who give informed consent

\section{Exclusion criteria}

- Subjects less than 18 years of age

- Presence of Comorbid Psychotic/ BPAD/ cognitive disorder/ neurological disorder

- Intellectual Disability

- Comorbid drug abuse/dependence other than Nicotine

- No reliable informant

- Those who refuse informed consent

After informed consent the patient and reliable informant were interviewed by the primary investigator. Sociodemographic data was collected using a proforma. Details of lapse, relapse and abstinence periods were meticulously reviewed and recorded after confirmation with the reliable informant. A relapse was defined as "a complete return to earlier dependence pattern of drinking”. A lapse was defined as "an intermittent drink not amounting to abuse or a full blown relapse". Abstinence was considered as "a state of zero lapse or relapse”. Medical and alcohol history, readmission details during the period between March 2018 and February 2019 and other relevant information was noted.

The in-patient charts of the subjects were retrieved from the medical records department for additional information during admission in the deaddiction ward. The SADQ score at admission, CIWA - Ar score and The Brief Substance Craving Score at the time of discharge were taken from the in-patient record. Details of withdrawal phase, presence or absence of withdrawal seizures, delirium tremens and the cooperation, motivation and involvement of the patient with the treatment during the in-patient stay was noted from the daily progress notes of the doctor and nursing record. History regarding the medical complications of alcohol and results of relevant blood investigations results were also obtained from the case record. The drugs prescribed at discharge were noted. The standardised rating scales used for assessment were Severity of Alcohol Dependence Questionnaire (SADQ), Clinical Institute Withdrawal Assessment of Alcohol Scale, Revised (CIWA-Ar), Rosenberg Self Esteem Scale, General Self Efficacy Scale, Depression Anxiety and Stress Scale, and Brief Substance Craving Scale. The OP note of the patient was reviewed for checking regularity of review, drug compliance and additional information of medical complications and consultations sought were noted. Cross consultations sought and medical comorbidities like diabetes and hypertension were also recorded.

\section{RESULTS}

A total of 88 patients who were admitted for deaddiction treatment in "Nambikkai" addiction care ward. Out of the 88 patients 9 patients did not satisfy the inclusion criteria, 1 patient had died in an RTA (under effect of alcohol) and 8 patients were either not reachable or did not turn up for the study or did not review with a reliable informant to cross verify and were hence not taken for study. A total of 70 patients were finally recruited.

The mean age of participant was $41.27 \pm 11.07$ years in the study population, minimum level was 22 and maximum level was 70 in the study population. Among the study population $54(77.14 \%)$ participants were referred by others and 16 (22.86\%) participants were referred by self. The drinking parameters in the patients showed that the mean age of first drink in years was $22.99 \pm 6.03$ in the study population and the mean duration of dependent pattern of drinking in months was $64.67 \pm 36.85$ in the study population. There was high frequency of family history of alcohol among the study

\begin{tabular}{|l|c|}
\hline Parameter & Mean \pm SD \\
\hline Age of first drink in years & $22.99 \pm 6.03$ \\
\hline Total duration of drinking in months & $207.86 \pm 102.86$ \\
\hline $\begin{array}{l}\text { Duration of dependent pattern of drinking } \\
\text { in months }\end{array}$ & $64.67 \pm 36.85$ \\
\hline $\begin{array}{l}\text { Age of onset of dependence pattern of } \\
\text { drinking }\end{array}$ & $35.17 \pm 9.27$ \\
\hline Family history of alcohol dependence & $23(32.86 \%)$ \\
\hline Family history of mental illness & $2(2.86 \%)$ \\
\hline Place of residence & $28(40.0 \%)$ \\
\hline Urban & $42(60.0 \%)$ \\
\hline Rural & $19(27.1 \%)$ \\
\hline Literacy & $24(34.3 \%)$ \\
\hline Primary & $24(38.6 \%)$ \\
\hline secondary & $16(22.9 \%)$ \\
\hline Graduate & $40(57.1 \%)$ \\
\hline Marital status & $14(19.9 \%)$ \\
\hline Single & $30(42.9 \%)$ \\
\hline Married & $40(57.1 \%)$ \\
\hline Separated/ Divorced/ Widow & $32(45.7 \%)$ \\
\hline Financial debts & $14(20.0 \%)$ \\
\hline Disulfiram & $17(24.3 \%)$ \\
\hline Antidepressants prescribed & \\
\hline H/O Jaundice after dependence drinking & \\
\hline RTA under intoxication & \\
\hline Table-1: Descriptive analysis of drinking related parameters in \\
\hline
\end{tabular}

\begin{tabular}{|l|c|}
\hline Parameters & Frequency (\%) \\
\hline Withdrawal seizures & $4(5.71 \%)$ \\
\hline Delirium tremens & $8(11.43 \%)$ \\
\hline Cooperation during IP stay & $56(80.00 \%)$ \\
\hline Motivation & $53(75.71 \%)$ \\
\hline Disulfiram & $40(57.14 \%)$ \\
\hline Antic raving medication & $63(90.00 \%)$ \\
\hline \begin{tabular}{|}
$|c|$ \\
Table-2: Descriptive analysis of clinical parameters in the study \\
population (N=70)
\end{tabular} \\
\hline
\end{tabular}




\begin{tabular}{|l|c|}
\hline Parameter & Mean \pm SD \\
\hline Substance craving score at discharge & $3.44 \pm 3.61$ \\
\hline $\begin{array}{l}\text { Duration of complete abstinence } \\
\text { after discharge in days }\end{array}$ & $197.57 \pm 173.77$ \\
\hline Total no. Of lapses in the last 1 year & $9.9 \pm 12.67$ \\
\hline $\begin{array}{l}\text { Total number of relapses in the last } \\
1 \text { year }\end{array}$ & $1(0,1)$ (median (IQR) \\
\hline $\begin{array}{l}\text { Duration of complete abstinence last } \\
1 \text { year(CDA) in days }\end{array}$ & $272.43 \pm 109.12$ \\
\hline $\begin{array}{l}\text { No. of readmissions for de-addiction } \\
\text { last } 1 \text { year }\end{array}$ & $1(0,1)$ (median (IQR) \\
\hline $\begin{array}{l}\text { No. of admissions for medical issues } \\
\text { last } 1 \text { year }\end{array}$ & $1(0,1)$ (median (IQR) \\
\hline $\begin{array}{l}\text { Duration of IP stay for de-addiction in } \\
\text { days last } 1 \text { year }\end{array}$ & $14.16 \pm 5.54$ \\
\hline SADQ score at admission & $23.5 \pm 7.53$ \\
\hline CIWA - ARSCORE after admission & $29.97 \pm 11.15$ \\
\hline Rosenberg self esteem scale score & $14.09 \pm 3.87$ \\
\hline General self efficacy scale score & $21.66 \pm 5.92$ \\
\hline DASS depression score & $10.53 \pm 5.39$ \\
\hline DASS anxiety score & $11.94 \pm 6.7$ \\
\hline DASS Stress Score & $14.46 \pm 6.86$ \\
\hline Table-3: Descriptive analysis of discharge related parameters \\
\hline
\end{tabular}

population (Table 1).

The difficulties in treatment included seizures, delirium tremens, poor motivation and use of disulfiram and anti craving medication (Table 2). At discharge the parameters such as craving and complete abstinence was mentioned in Table 3. At the end of 1 year the mean total no. of lapses was $9.9 \pm 12.67$ in the study population and the mean total number of relapses was $0.84 \pm 0.94$. The mean duration of complete abstinence last 1 year (CDA) in days was 272.43 \pm 109.12 . The mean no. of readmissions for de-addiction last 1 year was $0.23 \pm 0.57$ in the study population. The mean of standardised rating scales used for assessment were Severity of Alcohol Dependence Questionnaire (SADQ), Clinical

\begin{tabular}{|l|l|}
\hline Parameter & Frequency (\%) \\
\hline Current alcohol use status (last 2 weeks) \\
\hline Abstinent & $34(48.57 \%)$ \\
\hline Lapse & $10(14.29 \%)$ \\
\hline Relapse & $26(37.14 \%)$ \\
\hline Complete abstinence at one year & $22(31.43 \%)$ \\
\hline Yes & $48(68.57 \%)$ \\
\hline No & \begin{tabular}{r}
$|c|$ \\
\multicolumn{2}{|c|}{ Table-4: Descriptive analysis of alcohol use status (last 2 } \\
weeks) in the study population (N=70)
\end{tabular} \\
\hline
\end{tabular}

\begin{tabular}{|c|c|c|c|c|}
\hline \multirow[t]{2}{*}{ Parameter } & \multirow{2}{*}{$\begin{array}{l}\text { Un adjusted } \\
\text { odds ratio }\end{array}$} & \multicolumn{2}{|c|}{$95 \% \mathrm{Cl}$} & \multirow[t]{2}{*}{ P value } \\
\hline & & Upper & lower & \\
\hline Age of first drink in years & 1.053 & 1.003 & 1.105 & 0.037 \\
\hline Total duration of drinking in months & 1.151 & 1.046 & 1.267 & 0.004 \\
\hline Duration of dependent pattern of drinking in months & 1.002 & 0.997 & 1.007 & 0.368 \\
\hline Age of onset of dependence pattern of drinking & 1.058 & 0.999 & 1.120 & 0.052 \\
\hline Family history of alcohol dependence (Baseline=No) & 0.684 & 0.226 & 2.073 & 0.502 \\
\hline Family history of mental illness (Baseline=No) & 2.238 & 0.134 & 37.516 & 0.575 \\
\hline \multicolumn{5}{|l|}{ Place of residence (Baseline $=$ Urban) } \\
\hline Rural & 1.667 & 0.576 & 4.825 & 0.346 \\
\hline \multicolumn{5}{|l|}{ Literacy (Baseline=Primary) } \\
\hline secondary & 5.100 & 0.948 & 27.423 & 0.058 \\
\hline Graduate & 5.884 & 1.118 & 30.553 & 0.036 \\
\hline \multicolumn{5}{|l|}{ Marital status (Baseline= Single) } \\
\hline Married & 1.222 & 0.222 & 6.730 & 0.818 \\
\hline Separated/ Divorced/ Widow & 2.200 & 0.527 & 9.176 & 0.279 \\
\hline Financial debts (baseline=No) & 0.271 & 0.086 & 0.852 & 0.025 \\
\hline Disulfiram (baseline=No) & 3.696 & 1.174 & 11.633 & 0.025 \\
\hline Antidepressants prescribed (baseline=No) & 0.317 & 0.106 & 0.950 & 0.040 \\
\hline H/O Jaundice After Dependence Drinking (baseline=No) & 0.125 & 0.015 & 1.023 & 0.052 \\
\hline RTA Under Intoxication (baseline=No) & 0.095 & 0.012 & 0.773 & 0.028 \\
\hline
\end{tabular}

\begin{tabular}{|l|c|c|c|c|}
\hline Parameter & Un adjusted & \multicolumn{2}{|c|}{ 95 \% Cl } & \multirow{2}{*}{ P value } \\
\cline { 3 - 5 } & odds ratio & Upper & lower & \\
\hline Age of first drink in years & 1.029 & 0.958 & 1.106 & 0.431 \\
\hline Total duration of drinking in months & 1.086 & 0.963 & 1.226 & 0.178 \\
\hline Financial debts (baseline=No) & 0.289 & 0.075 & 1.110 & 0.071 \\
\hline Disulfiram (baseline=No) & 3.417 & 0.743 & 15.718 & 0.114 \\
\hline Antidepressants prescribed (baseline=No) & 0.354 & 0.094 & 1.329 & 0.124 \\
\hline RTA Under Intoxication (baseline=No) & 0.153 & 0.016 & 1.437 & 0.101 \\
\hline \multicolumn{2}{|l|}{ Table-6: Multivariate regression analysis of factors associated with Complete abstinence at one year in study population (N=70) } \\
\hline
\end{tabular}


Institute Withdrawal Assessment of Alcohol Scale, Revised (CIWA-Ar), Rosenberg Self Esteem Scale, General Self Efficacy Scale, Depression Anxiety and Stress Scale, and Brief Substance Craving Scale is mentioned in Table 4.

Univariate analysis had shown age at first drink in years, total duration of drinking in months and use of disulfiram and graduation as educational status are associated with higher odds of relapse. Having financial debts, prescription antidepressant intake and RTA under intoxication were associated with lower odds of relapse among the study population. (Table 5). None of the factors had shown any statistical significant association with relapse in the current study, on multivariate analysis. (Table 6)

\section{DISCUSSION}

The treatment of alcohol addiction has posed a bewildering challenge for modern society. Different individual characteristics are predictive of different types of treatment outcomes such as complete abstention, asymptomatic drinking, reduced but still problematic drinking, and unremitted impairment as drinking that leads to loss of control. ${ }^{9}$ Therefore, relapse as a central issue in the treatment of alcohol dependence warrants further study. ${ }^{10}$ Hence, in this study the factors associated with abstinence, lapse and relapse of drinking after an in-patient deaddiction programme was investigated.

The current study showed that only 22(31.43\%) participant were abstinent meaning most patient either had a lapse or a relapse. The mean total no. of lapses in the last 1 year was $9.9 \pm 12.67$ and mean total number of relapses in the last 1 year was $0.84 \pm 0.94$. the Cüneyt Evren, et al ${ }^{11}$ Among 102 alcohol dependent inpatients, $61.8 \%(n=63)$ were considered as relapsed to alcohol abuse. Few other studies showed higher relapse. ${ }^{7,10,12}$

In the current study the, the univariate analysis had shown age at first drink in years, total duration of drinking in months and use of disulfiram and graduation as educational status are associated with higher odds of relapse. Having financial debts, prescription antidepressant intake and RTA under intoxication were associated with lower odds of relapse among the study population. None of the scoring systems showed any associations. Cüneyt Evren, et al. ${ }^{11}$ showed that the relapsed was associated fewer regular visits to the outpatientclinic, attended the Outpatient Treatment Program on an irregular basis or not at all, made fewer social changes to protect themselves from a relapse or were not able to make any changes at all, and used the anti-craving medication irregularly or not at all.

Chauhan, V., et al. ${ }^{10}$ found that patients who had relapsed were found to have significantly more positive family history of substance use, past history of alcohol-related comorbidity, experienced a higher number of undesirable life events, and higher negative mood states and social anxiety and dysfunction in social, vocational, personal, family, and cognitive spheres compared to patients who had remained abstinent.

This study showed various factors that influence alcohol relapse. However, there are several limitations to this study. This cohort of single-centred inpatient participants are small and are hardly representative of the general population. The study was observational study with convenience sampling technique. Thus, the paper's conclusions are suggestive but may not be applicable to other populations. The outcomes were based upon self-report and physician-report without confirmation from significant others. Self-reported measures may contain information or social desirability bias. Future study must include large scale cohort study with a larger sample size to determine factors associated with relapse.

\section{ACKNOWLEDGEMENTS}

We acknowledge the technical support in data entry, analysis and manuscript editing by "Evidencian Research Associates"

\section{REFERENCES}

1. McElroy S, Farren CK. Predictive Factors for Relapse after an Integrated Inpatient Treatment Programme for Unipolar Depressed and Bipolar Alcoholics. Alcohol and Alcoholism. 2010;45(6):527-33.

2. Becker HC. Alcohol dependence, withdrawal, and relapse. Alcohol Res Health. 2008;31(4):348-61.

3. Kadam M, Sinha A, Nimkar S, Matcheswalla Y, De Sousa A. A Comparative Study of Factors Associated with Relapse in Alcohol Dependence and Opioid Dependence. Indian J Psychol Med. 2017;39(5):627-33.

4. Dawson DA, Grant BF, Stinson FS, Chou PS, Huang B, Ruan WJ. Recovery from DSM-IV alcohol dependence: United States, 2001-2002. Addiction. 2005;100(3):281-92.

5. Tempesta E, Janiri L, Bignamini A, Chabac S, Potgieter A. Acamprosate and relapse prevention in the treatment of alcohol dependence: a placebo-controlled study. Alcohol Alcohol. 2000;35(2):202-9.

6. Anupama Korlakunta, Swaroopa R S Chary, Reddy PKC. Reasons for relapse in patients with alcohol dependence. AP J Psychol Med 2012;13(2):108-4.

7. Evren C, Cetin R, Durkaya M, Dalbudak E. Clinical Factors Associated with Relapse in Male Alcohol Dependents During Six-Month Follow-up2010. 14-22 p.

8. Bottlender M, Soyka M. Impact of craving on alcohol relapse during, and 12 months following, outpatient treatment. Alcohol Alcohol. 2004;39(4):357-61.

9. Williams EC, Frasco MA, Jacobson IG, Maynard C, Littman AJ, Seelig AD ea. Risk factors for relapse to problem drinking among current and former US military personnel: A prospective study of the millennium cohort. Drug Alcohol Depend 2015;148(1):93-101.

10. Chauhan V, Nautiyal S, Garg R, Chauhan K. To identify predictors of relapse in cases of alcohol dependence syndrome in relation to life events. Industrial Psychiatry Journal. 2018;27(1):73-9.

11. Cüneyt Evren, Ercan Dalbudak, Rabia Çetin, Mine Durkaya, Selime Çelik, Çakmak D. Factors Related With Relapse in Male Alcohol Dependents: 12 Months Followup Study. The Journal of Psychiatry and Neurological Sciences. 2010;23(3):92-9.

12. Evren C, Durkaya M, Evren B, Dalbudak E, Cetin R. Relationship of relapse with impulsivity, novelty seeking and craving in male alcohol-dependent inpatients. Drug and alcohol review. 2012;31(1):81-90.

Source of Support: Nil; Conflict of Interest: None

Submitted: 01-05-2019; Accepted: 23-05-2019; Published online: 03-06-2019 